\title{
MIDAS
}

Museus e estudos interdisciplinares

$11 \mid 2020$

Dossier temático: "Perspetivas sobre o museu eclético"

\section{Caixas de tesouros. Um dossier sobre o museu ecléctico}

Wonder boxes. A dossier on the eclectic museum

Emília Ferreira, Joana d'Oliva Monteiro, Ana Carvalho e Raquel Henriques da Silva

\section{OpenEdition}

\section{Journals}

Edição electrónica

URL: http://journals.openedition.org/midas/2368

DOI: $10.4000 /$ midas. 2368

ISSN: 2182-9543

\section{Editora:}

Alice Semedo, Paulo Simões Rodrigues, Pedro Casaleiro, Raquel Henriques da Silva, Ana Carvalho

\section{Refêrencia eletrónica}

Emília Ferreira, Joana d'Oliva Monteiro, Ana Carvalho e Raquel Henriques da Silva, « Caixas de tesouros. Um dossier sobre o museu ecléctico », MIDAS [Online], 11 | 2020, posto online no dia 21 novembro 2020, consultado no dia 21 novembro 2020. URL : http://journals.openedition.org/midas/ 2368 ; DOI : https://doi.org/10.4000/midas.2368

Este documento foi criado de forma automática no dia 21 novembro 2020

\section{(i)(2)

Midas is licensed under a Creative Commons Attribution-NonCommercial-ShareAlike 3.0 International License 


\title{
Caixas de tesouros. Um dossier sobre o museu ecléctico ${ }^{1}$
}

\author{
Wonder boxes. A dossier on the eclectic museum
}

\author{
Emília Ferreira, Joana d'Oliva Monteiro, Ana Carvalho e Raquel Henriques \\ da Silva
}

1 Em 2018, cumpriram-se 170 anos sobre a morte de João Allen (Viana do Minho, 1 de Maio de 1781-Porto, 19 de Maio de 1848). Homem de educação cosmopolita, viajante infatigável e coleccionador de espírito enciclopedista ou ecléctico, João Allen abriu no Porto, em 1838, o Museu Allen, o primeiro estabelecimento público de carácter museológico, em Portugal, dotado de edifício criado de raiz para acolher uma colecção.

2 Para celebrar a sua memória, o Museu Nacional de Arte Contemporânea, o Museu Nacional Soares dos Reis, o Instituto de História da Arte (Faculdade de Ciências Sociais e Humanas da Universidade Nova de Lisboa - FCSH/NOVA) e a Faculdade de Belas Artes da Universidade do Porto organizaram Caixas de Tesouros. Congresso Internacional sobre o Museu Ecléctico. Como não podia deixar de ser, este encontro académico foi realizado no Porto, entre os dias 24 e 25 de Maio de 2018, no Museu Nacional Soares dos Reis. Herdeiro do Museu Portuense criado por João Baptista Ribeiro (1790-1868), em 1833, e do Museu Allen, duas instituições de teor ecléctico (embora por razões constituintes diversas - a primeira pelo seu carácter "oportunista" de recolha de obras de colecções anteriormente pertencentes a apoiantes da causa absolutista e a segunda dados os múltiplos interesses do coleccionador), a memória de João Allen foi aí também celebrada com a organização da exposição João Allen. Colecionar o Mundo. Comissariada por Rui Morais e José Costa Reis, exposição e congresso contaram com o incontornável apoio da família Allen, em particular por parte de José Alberto M. G. Allen, a quem agradecemos a disponibilidade e a partilha de dados do arquivo familiar.

3 Negociante de vinhos, herdando fortuna e actividade familiar, os estudos nos Estados Unidos da América e as viagens que, terminado o currículo, aí fez, terão decerto contribuído para nutrir o sonho do seu próprio museu que começará a concretizar anos mais tarde, em 1836, quando inicia a recuperação da sua antiga residência na Rua da Restauração, destruída em 1833 por ocasião do Cerco do Porto, mandando erigir «no 
fundo do jardim da casa» (Urcullu 1839, 153), uma galeria destinada a guardar e expor publicamente as suas colecções eclécticas, em grande parte reunidas nas outras múltiplas viagens que fez pela Europa.

O seu espírito viajante, inserido numa tradição de ilustração que Setecentos elevara a complemento pedagógico das classes altas europeias, terá sem dúvida contribuído não apenas para a constituição das colecções, mas igualmente para a sua vontade de partilha pública, cuja inspiração no museu do pintor norte-americano Charles Wilson Peale que, em 1782, em Filadélfia, criara o Peale's Museum, já foi apontada (Ferreira 2001). Nesses «tres salóes iguais de 22 palmos e meio de altura, 47 de comprimento, e 26 e meio de largura [...] a luz entra em todos elles por claraboias bem dispostas no tecto» (Urcullu 1839, 153). E neles «se amontoavam as obras de Arte e as variadas colecções de bugigangas desde os cabelos de D. Inês até um punhado de areia da praia do Mindelo. Os quadros cobriam as paredes de alto a baixo, à moda dos Museus e colecções dos Séculos XVIII e XIX» (Valente 1948, 22), conchas e outras «curiosas producções maritimas dignas da attenção d'um naturalista» (Urcullu 1839, 153). A presença de objectos tão diversos sob a atenção de um único coleccionador ecoa os vestígios do espírito moderno.

5 Figura inicial e incontornável da museologia portuguesa, a celebração da sua memória e legado, num momento em que estão já significativamente avançados entre nós os estudos sobre museus, constituiu mote para convidar a comunidade académica a participar num encontro propiciador de reflexão. Entre o espírito das colecções palacianas, as recolhas de ilustração do mundo, para deleite, instrução e inspiração, o museu, como casa das musas (aquelas que explicam os mistérios - Jaucourt apud Findlen 2004, 25), tem no modelo ecléctico moderno a sua raiz formal e conceptual. Mas nesse modelo radical insere-se também a tensão entre privado e público, como já notou a historiadora Paula Findlen, entre a tentação coleccionista e a vontade - e o prestígio social - da partilha.

As a concept which expressed a pattern of activity transcending the strict confines of museum itself, the idea of musaeum was an apt metaphor for the encyclopaedic tendencies of the period. Most compelling about the usage of the term museum was its ability to be inserted into a wide range of discursive practices. Linguistically, museum was a bridge between social and intellectual life, moving effortlessly between these two realms, and in fact pointing to the fluidity and instability of categories such as 'social' and 'intellectual', and 'public' and 'private', as they were defined during the late Renaissance. (Findlen 2004, 23)

6 Semelhante modelo aprofundou-se em Setecentos, prosperando ainda ao longo de Oitocentos. Nesse sentido, considerámos para este encontro o conceito de museu do século XVIII, herdeiro ainda do modelo moderno de inspiração enciclopédica, até às instituições contemporâneas, à semelhança da criada por este ilustrado coleccionador portuense de ascendência inglesa, abordando um arco cronológico de Setecentos até meados de Oitocentos, a época por excelência do museu ecléctico, ou seja, do museu cuja organização decorre ainda muito proximamente da herança dos gabinetes de curiosidades e da sua evolução enciclopedista, cuja história continua a interessar os investigadores, sobretudo a sua origem, como o prova a contínua actualização do clássico The Origins of Museums: The Cabinet of Curiosities in Sixteenth and Seventeenth Century Europe que, desde a sua edição original em 1985, à mais recente (2017), com edição de Oliver Impey e Arthur MacGregor, continua a ser considerado o grande volume de referência sobre o assunto. 
7 Como vimos, o modelo do museu ecléctico expandiu-se no tempo, adentrando os séculos XVIII e XIX e inspirando ainda coleccionadores, museólogos e historiadores em pleno século XX, reforçando a relevância desse passado original no carácter identitário da própria instituição museológica e no legado que ainda constitui para o imaginário colectivo. A chamada de trabalhos para Caixas de Tesouros. Congresso Internacional sobre o Museu Ecléctico foi, por isso, pensada no sentido de apurar a persistência desse modelo em Portugal, e decorrentemente, pensada com o objectivo de tomar o pulso a novos avanços na investigação das colecções eclécticas entre nós, além de, simultaneamente, potenciar o estabelecimento de relações com instituições congéneres coevas internacionais, inserindo assim esse capítulo da história dos museus portugueses, numa necessária e complementar perspectiva comparativa.

8 Abrindo o leque de propostas a abordagem de temas como os coleccionadores e as colecções, a relação entre enciclopedismo e eclectismo, a ilustração, a arquitectura, a museologia, a pedagogia e os públicos - em suma, a cidadania e envolvimento público - o Congresso contou com participantes de Portugal, Brasil, Holanda e Estados Unidos.

9 Ao congresso apresentaram-se 20 comunicações escolhidas entre várias dezenas de propostas. Apesar da grande qualidade dos trabalhos do Congresso, a selecção feita para o presente dossier da MIDAS prendeu-se com a novidade que as propostas apresentaram sobre o estado de investigação de alguns núcleos museológicos concretos e o consequente interesse e contributo para a análise do modelo ecléctico (ou, como vimos, do museu com inspiração enciclopédica).

10 Como confirmámos no Congresso, integrando-se na tradição desta teorização, a abordagem relativa à tipologia museológica em causa foi focada na análise de casos particulares de aspectos relativos a coleccionadores e colecções, assim ilustrando o modo como da biografia decorre a colecção e como da colecção toma corpo o museu e a percepção que dele temos - algo que, uma vez mais, se integra na tradição do museu como instituição e exercício de contextualização (Findlen 2004, 31).

11 As palavras-chave dos artigos seleccionados delineiam já algumas das muitas linhas de interesse dessa tipologia museológica, na ligação entre tempos, criações artísticas e elementos exóticos, raros ou atractivos da natureza física do mundo, aí incluídas todas as classes de seres, desde a biologia à mineralogia, num registo que Roland Shaer, em 1994, resumia como parte integrante da aura de que o museu ainda goza, enquanto «lieu où s'exposent, avec leur mystère, les mécanismes de la création» (Shaer 1994, 40). Tais palavras integram desde o nome de coleccionadores, artistas e museus (Jean Pillement, Ferreira das Neves, Maria Graham, Pedro Eugénio Daupias, Francisco Tavares Proença Júnior, Fernando de Castro, Museu Machado de Castro, Museu Francisco Tavares Proença Júnior, Museu Nacional Soares dos Reis), conceitos, disciplinas históricas e acções como estética, arqueologia, artes decorativas, viagem, psicologia, fantasmagoria ou excesso.

12 O acesso a nova documentação e a renovadas propostas museográficas enformam os dois primeiros textos, de Paula Mesquita Leite Santos e de Marize Malta. No primeiro caso, mergulhando no fundo antigo do Museu Nacional Soares dos Reis e no depósito da Câmara Municipal do Porto, o artigo de Paula Mesquita Leite Santos, fruto da investigação desenvolvida no âmbito de um projecto de doutoramento na Universidade de Santiago de Compostela, aborda a presença de "Jean Pillement (Lyon, 1728-1808) e os colecionadores do Porto. Pintura nos Museus Nacionais de Soares dos Reis e de Arte Antiga", mostrando os processos de afirmação do artista de Lyon, em Portugal na 
década de 1780, e a sua importância na criação de núcleos pictóricos de colecções em Portugal, com particular incidência para as portuenses.

No segundo caso, investigando as relações transnacionais constitutivas de colecções, Marize Malta explora, no artigo "Gostos ecléticos em coleções, repercussões em museus nacionais: o caso da coleção Ferreira das Neves", a colecção ecléctica do brasileiro Jerônimo Ferreira das Neves e da sua mulher, Eugênia das Neves, durante a sua estada lisboeta, nas décadas de 1880-1890. Sublinhando o quanto o gosto pessoal dos coleccionadores contribuiu para o carácter complexo da colecção, que reuniu livros raros, numismática, medalhística, obras de arte e objectos quotidianos, Marize Malta recorda o percurso histórico desse espólio, em particular da parte legada à Escola Nacional de Belas Artes do Rio de Janeiro, antiga Academia Imperial, em 1947, vindo a integrar, em 1979, o acervo do Museu D. João VI, espaço museológico dessa instituição académica. A recente renovação museográfica desse museu, com a recuperação do eclectismo inicial, possibilitou uma nova leitura das coleç̧ões de que a investigadora nos dá conta, sustentando renovado debate sobre o modo como os legados patrimoniais aos museus nacionais brasileiros mantêm aberto um pertinente questionamento quanto à abordagem destas colecções na contemporaneidade.

Reforçando o contributo das coleccionadoras na constituição de colecções, apontado por Marize Malta, retirando o museu do âmbito meramente masculino do olhar do coleccionador (Findlen 2004, 37), também Maria de Fátima Lambert aborda um outro modo de ver o museu (aqui definido, ainda como moderno e lato, como reconhecimento, cartografia e arquivo do mundo, nomeadamente através do registo em livro) através das "Viagens ecléticas, residências e obras: Maria Graham artista-autoraviajante" e que persiste nas viagens setecentistas de ilustração e na decorrente memória. Lambert, além da introdução de mais um artigo de relevância transnacional, analisa o pensamento sistemático sobre viagens, desde a primeira estada da viajante inglesa Maria Graham na Índia, os seus périplos europeus e as residências no Brasil. Com experiências críticas que resultaram em cerca de 10 livros de viagem, nomeadamente $O$ diário de uma Viagem ao Brasil e de uma Estada nesse País durante parte dos anos de 1821, 1822 e 1823, as suas reflexões e registos iconográficos dão testemunho de inúmeras missões científicas e artísticas, reflectindo um tempo de recolhas filosóficas constitutivas do pensamento enciclopedista, e revelando perspectivas críticas sociológicas potenciadoras de mais profunda reflexão.

O envolvimento da biografia no curso da paixão coleccionadora é continuado por Ramiro A. Gonçalves, no seu artigo "Para além da Pintura. Alguns apontamentos sobre as outras coleções do conde Daupias", um dos mais renomados coleccionadores em Portugal, no final de Oitocentos. Com uma colecção que incluía escultura, cerâmica, têxteis, mobiliário, ourivesaria e pintura, o autor destacou esta última, pela qualidade de algumas das suas obras constituintes, o alinhamento com o então dominante gosto parisiense, debruçando-se, contudo, também sobre as demais colecções, destacando os objectos mais comentados pelos visitantes da Galeria e abordando o destino funesto desta colecção, cuja dispersão reflectiu os inúmeros desaires pessoais de Daupias.

o desígnio pessoal e a importância crescente da instituição museu no plano nacional e local estão também registados no artigo que Ana Cristina Martins intitulou "Páginas da vida de um jovem arqueólogo: Francisco Tavares Proença Júnior (1883-1916)", destacando o papel do arqueólogo e coleccionador que fundaria o Museu Municipal de Castelo Branco. 
17 Duarte Manuel Freitas aborda o surgimento de outro museu, com o artigo "Para uma árvore genealógica museológica: o caso singular do Museu Machado de Castro", um dos dois textos que, neste dossier, se dedicam ao incontornável papel dos museólogos. Considerando o Museu Nacional Machado de Castro, fundado em 1911, uma confluência de três fenómenos museológicos oitocentistas ocorridos em Coimbra, o autor delineia o "passado genético" do museu, o seu contributo para a criação de dois espaços museológicos no distrito onde se insere, e o modo como as decisões dos seus directores foram moldando a face e os destinos do museu, introduzindo aqui a questão biográfica na prática museológica.

18 Fechamos este dossier com a investigação de Raquel Henriques da Silva sobre "A CasaMuseu Fernando de Castro: das colecções e das fantasmagorias", que reflecte sobre a existência de um espaço ainda vastamente afastado do conhecimento do grande público e dependente da tutela do Museu Nacional Soares dos Reis, embora (devido a constrangimentos vários) raramente acessível a visita pública. Apesar de reunida em pleno século XX, esta colecção apresenta várias particularidades, sugerindo diversos modos de viagem no tempo. Por um lado, a casa não foi originalmente pensada para espaço museológico, mas para habitação de Fernando de Castro, um comerciante cujo sucesso nos negócios lhe permitiu custear as inúmeras aquisições de talha dourada, que reuniu no espaço doméstico, destinando a sua actividade aos seus olhos apenas (e aos de uma minoria escolhida de convivas). Por outro, esse aspecto compulsivo de acumulação estrictamente pessoal e nem sequer museologicamente documentada na sua origem - e que apenas no final da vida de Fernando de Castro parece ter tido alguma intenção de partilha - recorda também modelos mais antigos de gabinetes secretos, destinados a usos muito exclusivos, reforçando, como nota a autora, «a dimensão aurática da sua particularidade».

19 Compreendendo este dossier investigações sobre o museu ecléctico do século XVIII ao $\mathrm{XX}$, em Portugal, com algumas pontes para projectos transnacionais, constatamos com entusiasmo que os artigos aqui reunidos demonstram a vitalidade não apenas do modelo do museu ecléctico, como ainda da investigação em seu torno, considerando os coleccionadores e a sua diversidade e relevância para a definição de espólios; o museu enquanto espaço arquitectónico, inserido num contexto urbano, social, histórico, cultural e político específico; o museu enquanto conceito aberto (ao mundo e à sua experiência e registo); e, ainda, o incontornável papel dos museólogos, determinando a face da instituição pela sua cultura e perspectiva científica decorrente.

Esperamos que este dossier constitua mais um elemento de investigação e reflexão algo a que a revista MIDAS já nos habituou. $O$ aprofundamento dos estudos de museus entre nós, reiterado também pelas recensões sobre teses de doutoramento recentemente publicadas em livro e que se debruçaram sobre temas museológicos (análises de Paulo Simões Rodrigues, sobre o livro de Hugo Xavier, O Marquês de Sousa Holstein e a Formação da Galeria Nacional de Pintura da Academia de Belas Artes de Lisboa; de João Luís Cardoso, a propósito da obra de Elisabete J. Santos Pereira, Colecionismo Arqueológico e Redes do Conhecimento: Atores, Coleções e Objetos (1850-1930); e de Vera Mariz à obra de Maria João Vilhena de Carvalho, resultante da sua tese de doutoramento, $A$ Constituição de uma Coleção Nacional. As Esculturas de Ernesto Vilhena) e a atenção de investigadores portugueses à actividade museológica e curatorial internacional (de que fica o registo de Susana S. Martins sobre a exposição The Art of Collecting) são tantas outras provas do interesse e da dinâmica desta investigação e da sua actualidade. 
21 Não poderíamos terminar este editorial sem agradecer a inestimável colaboração de Ana Carvalho, co-editora deste número da MIDAS, e de Raquel Henriques da Silva, que connosco coordenaram este dossier sobre o vibrante tema do museu ecléctico.

\section{BIBLIOGRAFIA}

Ferreira, Emília. 2001. "História dos Museus Públicos de Arte no Portugal de Oitocentos: 1833-1884." Dissertação de mestrado em História da Arte, Faculdade de Ciências Sociais e Humanas, Universidade Nova de Lisboa.

Findlen, Paula. 2004. "The Museum. Its Classical Etymology and Renaissance Genealogy." In Museum Studies. An Anthology of Contexts, ed. Bettina Messias Carbonell, 23-50. Oxford: Blackwell Publishing.

Impey, Oliver, e Arthur MacGregor. 2017 (1985). The Origins of Museums: The Cabinet of Curiosities in Sixteenth and Seventeenth Century Europe. Oxford: Ashmolean Museum.

Shaer, Roland. 1994. "Des Encyclopédies Superposées." La Jeunesse des Musées: Les Musées de France au XIXe Siècle, ed. Chantal Georgel, 38-51. Paris: Musée d'Orsay. Réunion des Musées Nationaux.

Urcullu, José de. 1839. Tratado Elementar de Geographia Astronomica, Fisica, Historica ou Politica, Antiga e Moderna. 2. ed. Porto: [s.n.].

Valente, Vasco. 1948. João Allen (1781-1848) Soldado, negociante, artista e amigo das artes. Comemorando o 1 o centenário do seu falecimento. Porto: [s.n.].

\section{NOTAS}

1. As autoras escrevem de acordo com a antiga ortografia.

\section{AUTORES}

\section{EMÍLIA FERREIRA}

Lisboa, 1963. Licenciada em Filosofia (Faculdade de Letras da Universidade de Lisboa), mestre e doutora em História da Arte Contemporânea (Faculdade de Ciências Sociais e Humanas da Universidade Nova de Lisboa - FCSH/NOVA), respectivamente com a dissertação "História dos Museus Públicos de Arte no Portugal de Oitocentos: 1833-1884", e a tese Lisboa em Festa: a Exposição Retrospetiva de Arte Ornamental Portuguesa e Espanhola, 1882, Antecedentes de um Museu (Direção-Geral do Património Cultural/Caleidoscópio, 2017). Coordenadora, com Joana d'oliva Monteiro e Raquel Henriques da Silva, do Dicionário Quem é Quem na Museologia Portuguesa. 
Investigadora integrada do Instituto de História da Arte (FCSH/NOVA) e investigadora associada aos projectos Social Sciences and Humanities Research Council (SSHRC), University of Victoria, British Columbia, Canadá. É, desde Dezembro de 2017, directora do Museu Nacional de Arte Contemporânea (Lisboa).

Instituto de História da Arte, Faculdade de Ciências Sociais e Humanas, Universidade de Lisboa, Colégio Almada Negreiros, Campus de Campolide, 1070-312 Lisboa, Portugal, meofster@gmail.com

\section{JOANA D'OLIVA MONTEIRO}

Investigadora integrada do Instituto de História da Arte (IHA) da Faculdade de Ciências Sociais e Humanas da Universidade Nova de Lisboa (FCSH/NOVA) - Grupo de investigação Museum Studies (MuSt). Doutora em História da Arte, especialização Museologia e Património Artístico, pela mesma Universidade, na qualidade de bolseira de investigação da Fundação para a Ciência e a Tecnologia, com a tese "Um Modelo Operativo de Avaliação de Exposições. Estudo de Caso: Museu Nacional de Arte Antiga" (2017). Mestre em Museologia pela NOVA FCSH, com a dissertação "A Galeria de Exposições Temporárias do Mosteiro de Alcobaça-Reflexões e Contributos na Óptica do Discurso Expositivo" (2010), distinguida pela Associação Portuguesa de Museologia (APOM) com o Prémio de Melhor Estudo sobre Museologia (2011). Licenciada em História da Arte e Património pela Faculdade de Letras da Universidade de Lisboa (2006).

Instituto de História da Arte, Faculdade de Ciências Sociais e Humanas, Universidade de Lisboa, Colégio Almada Negreiros, Campus de Campolide, 1070-312 Lisboa, Portugal, joana.oliva.monteiro@gmail.com

\section{ANA CARVALHO}

Investigadora de pós-doutoramento no Centro Interdisciplinar de História, Culturas e Sociedades (CIDEHUS) da Universidade de Évora com bolsa da Fundação para a Ciência e a Tecnologia (FCT). Doutoramento em História e Filosofia da Ciência, especialização em Museologia e mestrado em Museologia (Universidade de Évora). Membro do Grupo de Projecto Museus no Futuro (2019-2020), uma iniciativa do Ministério da Cultura. Colaborou como investigadora no projecto Mu.SA - Museum Sector Alliance (2016-2020). Coordenou o Boletim do ICOM Portugal (2014-2018). A sua investigação tem-se centrado em temas da história da museologia e da museologia contemporânea (museus e património cultural imaterial, diversidade cultural, participação, tecnologias e transformação digital, políticas públicas para os museus e património cultural).

CIDEHUS - Centro Interdisciplinar de História, Culturas e Sociedades da Universidade de Évora, Palácio do Vimioso, Largo do Marquês de Marialva, n.ำ 8, Apartado 94, 7000-809 Évora, Portugal, arcarvalho@uevora.pt

\section{RAQUEL HENRIQUES DA SILVA}

Professora na Faculdade de Ciências Sociais e Humanas da Universidade Nova de Lisboa, Departamento de História da Arte de que é coordenadora executiva desde 2015. Lecciona seminários do mestrado em História da Arte do século XIX e do mestrado em Museologia; é coordenadora do curso de doutoramento em História da Arte. Autora de estudos de investigação e divulgação nas áreas do urbanismo e arquitectura (século XIX-XX), artes plásticas e museologia. Comissária de exposições de arte. Foi directora do Museu do Chiado (1994-1997) e do Instituto Português de Museus (1997-2002). Integrou o Conselho de Administração da Fundação de Serralves (2000-2006) e, actualmente, integra o Conselho de Administração da Fundação ArpadSzenes-Vieira da Silva. É directora científica do Museu do Neo-Realismo desde 2018. 
Instituto de História da Arte, Faculdade de Ciências Sociais e Humanas, Universidade de Lisboa, Colégio Almada Negreiros, Campus de Campolide, 1070-312 Lisboa, Portugal,

raquelhs10@gmail.com 